\title{
Special section on 'Asia's regional business cycle: Is it for real? - Guest editor's preface'
}

\author{
Hoffmann, Mathias
}

DOI: https://doi.org/10.1111/j.1468-0106.2011.00573.x

Posted at the Zurich Open Repository and Archive, University of Zurich ZORA URL: https://doi.org/10.5167/uzh-72976

Journal Article

Accepted Version

Originally published at:

Hoffmann, Mathias (2012). Special section on 'Asia's regional business cycle: Is it for real? - Guest editor's preface'. Pacific Economic Review, 17(1):104-105.

DOI: https://doi.org/10.1111/j.1468-0106.2011.00573.x 


\section{Special Section on}

\section{"Asia's regional business cycle: is it for real? - Guest editor's preface"}

\section{Mathias Hoffmann, University of Zurich \& CESifo *}

Amidst the current global economic turmoil and with prospects for a quick recovery dimming in Europe and the United States, hopes have turned to Asia' emerging economies to sustain global economic growth. When the Lehman collapse in autumn 2008 ushered in the globally most synchronized downturn since the Great Depression, notions of a 'decoupling' of business cycle patterns in the region from those in the US and other industrialized economies were quickly dismissed by many observers. However, Asia's recovery since then has been vigorous and trend growth has continued to be robust. Is this for real? Has Asia's growth become self-sustained? Or will the need for fiscal retrenchment in Europe and the US and the as of yet unsolved crisis of household and financial sector balance sheets in many western economies eventually feed through into lower global demand, eventually plunging China and the economies in the region into a prolonged slowdown?

This short section brings together three papers that analyze these questions from three different angles. The first, by He Dong and Liao Wei, argues that Asia's decoupling is more pronounced in trends rather than in cycles. This trend decoupling suggests, the authors argue, that structural forces, such as increased vertical trade linkages in the region - now contribute more to regional synchronization than global demand shocks. Clearly, these findings bode well for a successful transition from the region's traditional export-led growth model to a more domestically led growth pattern sustained by domestic consumption.

The second paper, by Ippei Fujiwara and Koji Takahashi, distinguishes between real and financial linkages. The authors identify what they call a macro-finance dissonance: Asia's economy continues to 
be very synchronized with the world financially and US financial markets continue to lead fluctuations in stock and bond prices around the world. On the real side, however, China's business cycle increasingly impacts on the world economy as a whole. It seems that the extent of this feedback is not (yet) strongly reflected in financial markets. The authors leave a detailed explanation of this interesting stylized fact for future research. But at this stage it may be allowed to speculate that, as China's financial markets develop and open up, this macro-finance dissonance may eventually be resolved.

The third paper, by Michael Artis and Toshihiro Okubo, takes a long-run historical and comparative perspective on regional and global synchronization. By putting Asia's current experience in to a wider historical context, Artis and Okubo show that previous experiences of emerging regional business cycles have deep historical roots: the European business cycle that emerged in the run-up to the European Monetary Union can be predicted from trade patterns that prevailed at the turn of the previous century, during the period of the classical Gold Standard. No historical patterns of similar strength appear discernible for Asia, even though the region has been engaged in substantial bilateral trade ever since.

Read together, the three papers seem to suggest that current macroeconomic evidence is insufficient to answer the initial question conclusively: decoupling appears more robust and more persistent than most economists would have thought possible before the crisis. But decoupling is clearly not apparent in financial markets and, as the region's share in the world economy grows, there is increasing feedback from emerging Asia to the industrialized world. This seems to limit the scope for decoupling, though it may suggest a certain degree of insulation of China's growth from the adverse factors affecting western economies. Finally, it is important to note that East Asia has no historical tradition of bilateral trade fostering close business cycle ties - and no concomitant tradition of major political initiatives designed to foster convergence - that would allow the development of a very clearly discernible regional 
business cycle as has been the case in Europe.

More research will be needed. This special section is intended to encourage it. 